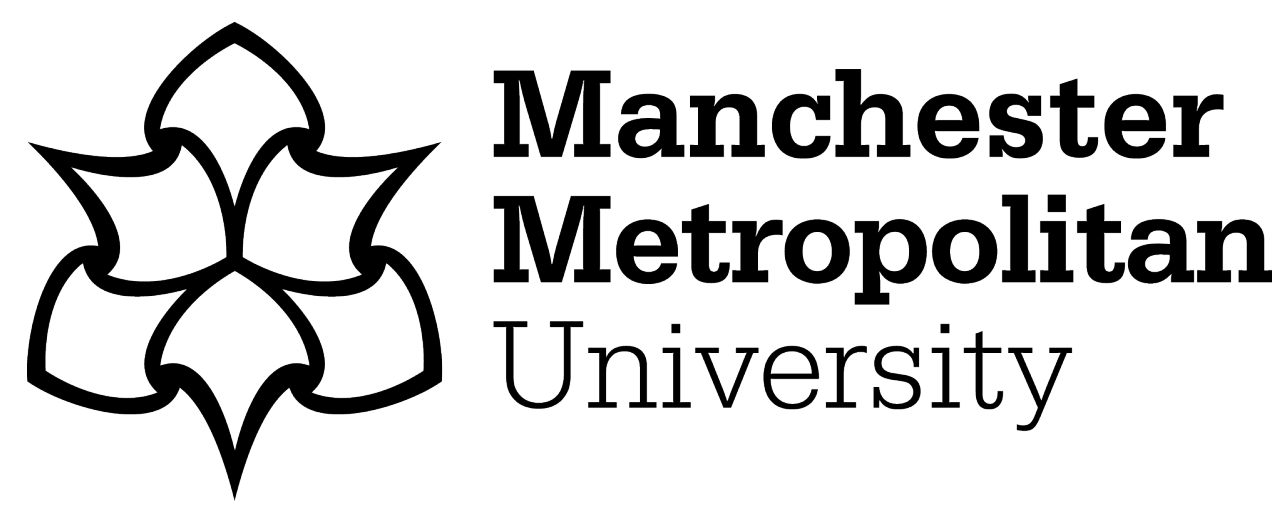

Faber, Jasper, Lee, David ORCID logoORCID: https://orcid.org/0000-00025984-8861, Becken, Susanne, Corbett, James J, Cumpsty, Nick, Fleming, Gregg, Longva, Tore, Tronstad Lund, Marianne and Smith, Tristan (2020) Bridging the gap - the role of international shipping and aviation. In: Emissions Gap Report 2020. United Nations Environment Programme. ISBN 978-92-807-3812-4

Downloaded from: https://e-space.mmu.ac.uk/627068/

Version: Published Version

Publisher: United Nations Environment Programme

Please cite the published version 


\title{
5 Bridging the gap - the role of international shipping and aviation
}

\author{
Lead authors: \\ Jasper Faber (CE Delft, the Netherlands) and David S. Lee (Manchester Metropolitan University, UK)
}

\section{Contributing authors:}

Susanne Becken (Griffith University, Australia), James J. Corbett (Energy and Environmental Research Associates, USA), Nick Cumpsty (Imperial College London, UK), Gregg Fleming (Volpe Center, U.S. Department of Transportation, USA), Tore Longva (DNV GL, Norway), Marianne Tronstad Lund (Center for International Climate Research - CICERO, Norway), Tristan Smith (University College London, UK)

\subsection{Introduction and framing}

Emissions from the shipping and aviation sectors have increased in the past decades (though they reduced in 2020 due to the COVID-19 pandemic) and accounted for approximately $2 \mathrm{GtCO}_{2}$ in 2019 (International Maritime Organization [IMO] 2020; Lee et al. in press). About twothirds of these emissions are international, meaning they are not included in national totals reported to the United Nations Framework Convention on Climate Change (UNFCCC) and are instead added as memo items. Although international emissions are not covered under the nationally determined contributions (NDCs) of most signatories to the Paris Agreement, article 4 commits its signatories to reducing all anthropogenic greenhouse gas ( $\mathrm{GHG}$ ) emissions. No sector is exempt from this commitment. At present, the International Civil Aviation Organization (ICAO) and the International Maritime Organization (IMO) are the specialized United Nations agencies tasked with addressing international GHG emissions. Shipping and aviation both largely depend on liquid fossil fuels and have inherently long technology development and fleet turnover times, which make it difficult for the sectors to decarbonize. In addition to GHG emissions, both sectors emit other emissions that contribute to climate change, such as nitrogen oxides $\left(\mathrm{NO}_{x}\right)$, water vapour, back carbon (soot) and sulphur dioxide $\left(\mathrm{SO}_{2}\right)$ (Eyring et al. 2010; Eide et al. 2013; Lee et al. in press).

This chapter presents current and projected emissions to assess how much the international transport sectors are contributing to the emissions gap (section 5.2). Section 5.3 analyses the technical, operational and fuel options available to decarbonize shipping and aviation. Section 5.4 contrasts the projected emissions with global emissions pathways required to meet the Paris Agreement temperature goals in order to assess when, and to what extent, the decarbonization options should be implemented, while also evaluating the current policy goals in the context of the Paris Agreement. Section 5.5 concludes the findings.

\subsection{Current emissions, projections and drivers}

Increased globalization and diversified economies have led to a rapid growth in human mobility and the transport of goods. In turn, increasingly connected and affordable transport systems have further enabled globalization and associated economic development, bringing socioeconomic benefits to parts of the population. In addition to rising global average incomes, this has caused an increase in consumer demand for travel and traded goods, reaching record levels in 2019 with 1.4 billion international tourists (World Tourism Organization [WTO] 2019), 4.5 billion passengers, 61.3 million tons of air freight (International Air Transport Association [IATA] 2020a) and 11 billion tons of world seaborne trade recorded (United Nations Conference on Trade and Development [UNCTAD] 2019).

\subsubsection{Shipping}

GHG emissions from shipping, principally carbon dioxide $\left(\mathrm{CO}_{2}\right)$, totalled approximately $1 \mathrm{GtCO}_{2}$ in 2018 , the latest year for which detailed data are available (IMO 2020), with small additional emissions of methane $\left(\mathrm{CH}_{4}\right)$ and nitrous oxide $\left(\mathrm{N}_{2} \mathrm{O}\right) . \mathrm{CH}_{4}$ emissions have risen in recent years (albeit from a low base), due to the increased number of liquified natural gas (LNG)-fuelled ships. Shipping also emitted around 100,000 tons of black carbon (soot) in 2018, which is a short-lived climate pollutant that contributes to warming (Comer et al. 2017; IMO 2020). Other non- $\mathrm{CO}_{2}$ emissions (such as $\mathrm{NO}_{x}$ and $\mathrm{SO}_{2}$ ) cause net cooling effects, largely through the formation of low-level clouds from $\mathrm{SO}_{2}$ emissions (Fuglestvedt et al. 2009; Peters et al. 2012), although in January 2020, new air quality protection regulations for shipping entered into force, with the aim of reducing these emissions (Sofiev et al. 2018). 
In 2018, international voyages (those between ports in different countries) were responsible for 71 per cent of the sector's $\mathrm{CO}_{2}$ emissions (IMO 2020). ${ }^{1}$ Many of the ships that undertake international voyages also undertake domestic voyages. For example, a ship may load cargo in a port in one country, sail to a second port in that same country to load more cargo, and then sail to a port in another country to discharge cargo.

$\mathrm{CO}_{2}$ shipping emissions in 2018 were lower than in 2008 which was the historic peak. As shown in figure 5.1, seaborne trade and emissions were closely correlated between 1990 and 2008. At the end of 2007, an oversupply of ships led ships to reduce their speed in order to ensure optimal utilization of their cargo capacity, which consequently reduced emissions. This became even more prominent in 2008 due to the decline in transport demand caused by the global financial crisis. After 2008, ships permanently reduced their speed by about 10-20 per cent compared with their pre-2008 speed, and the average size of bulkers and container ships increased, resulting in further efficiency improvements.

Figure 5.1. Historical and projected international shipping emissions and trade metrics, indexed in 2008, for 1990-2050

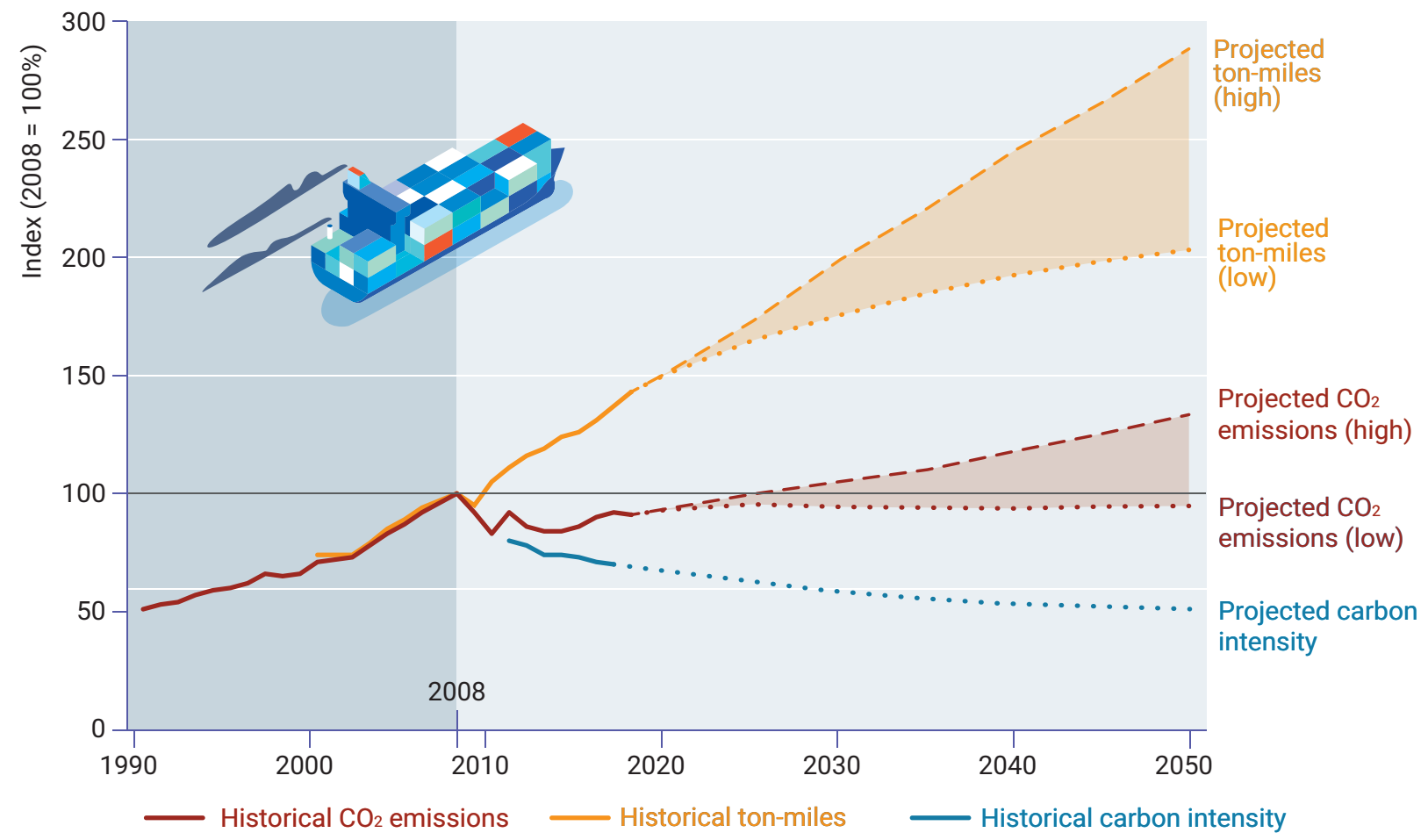

Note: The effect of COVID-19 is not included.

Source: IMO (2020)

In future decades, $\mathrm{CO}_{2}$ emissions from shipping are projected to increase by 4-50 per cent from 2018 levels according to a range of plausible business-as-usual (BAU) scenarios that assume no further policy intervention on shipping emissions. This is due to the projected 40-100 per cent increase in transport demand, despite projected fuel efficiency improvements in some scenarios (Faber et al. 2016; IMO 2020). The main driver of the increase in transport demand is the projected growth in wealth, as there is a strong positive correlation between gross domestic product (GDP) per capita and maritime transport demand.

DNV GL (2020) estimates that COVID-19 will cause the total demand for seaborne transportation to decline by approximately 8 per cent in 2020, which will vary between cargo segments. By May 2020, some segments had seen an increase in activity compared with the same period in 2019, though container shipping capacity reduced by 6 per cent. Manufacturing is typically more affected in an economic downturn, which in turn reduces the demand for seaborne trade of manufactured products and base materials. IMO (2020) did not foresee COVID-19 as impacting emissions projections for 2030 and beyond.

\subsubsection{Aviation}

In 2018, global $\mathrm{CO}_{2}$ aviation emissions were approximately $1 \mathrm{Gt}$ (Lee et al. in press), of which about 65 per cent were international and 35 per cent domestic (Fleming and de

1 According to another definition of international shipping emissions, which refers to ship types rather than to voyages, 87 per cent of emissions are international (IMO 2020) 
Lépinay 2019). ${ }^{2}$ Emissions have increased by around 27 per cent over the last five years (an average annual increase of 4.6 per cent based on International Energy Agency (IEA) data), while passenger numbers have grown by 38 per cent (based on International Air Transport Association (IATA) data)

Despite increased access to mobility, aviation remains the preserve of high-income earners. Over 60 per cent of demand for aviation comes from inhabitants of highincome countries (Becken and Pant 2019). According to Gössling and Humpe (2020), approximately 1 per cent of the world's population account for more than half of the total emissions from passenger air travel, thus revealing a strong equity dimension to aviation as a consumer sector. Chapter 6 discusses some of the demand-side issues related to aviation emissions and how these can be managed and reimagined in a post-pandemic future.

$\mathrm{CO}_{2}$ emissions from international aviation, along with related non- $\mathrm{CO}_{2}$ emissions from water vapour, NOx and soot/ aerosol particles have a net warming impact on climate, with the total impact of both types of emission estimated at 3.5 per cent of all drivers of climate change from human activities (Lee et al. in press). Historical $\mathrm{CO}_{2}$ emissions from global aviation result in approximately 34 per cent of present-day aviation-related effective radiative forcing (ERF), with non- $\mathrm{CO}_{2}$ impacts accounting for approximately 66 per cent of ERF from (global) aviation (Lee et al. in press).

The aviation industry expects emissions to increase in the coming decades, despite the current COVID-19 pandemic, which is currently estimated to impact traffic until at least 2024 (IATA 2020b). The latest emissions projections from the eleventh meeting of the ICAO Committee on Aviation Environmental Protection (CAEP/11) (figure 5.2, prepared prior to the pandemic) suggest that emissions of international aviation will increase from about $0.5 \mathrm{GtCO}_{2}$ of emissions (2015) to 1.2-1.9 $\mathrm{GtCO}_{2}$ by 2050 (Fleming and de Lépinay 2019). Revenue ton-kilometres (a metric for transport work in the aviation sector) are also expected to increase fourfold in the same period.

Figure 5.2. Projections of $\mathrm{CO}_{2}$ emissions for international aviation

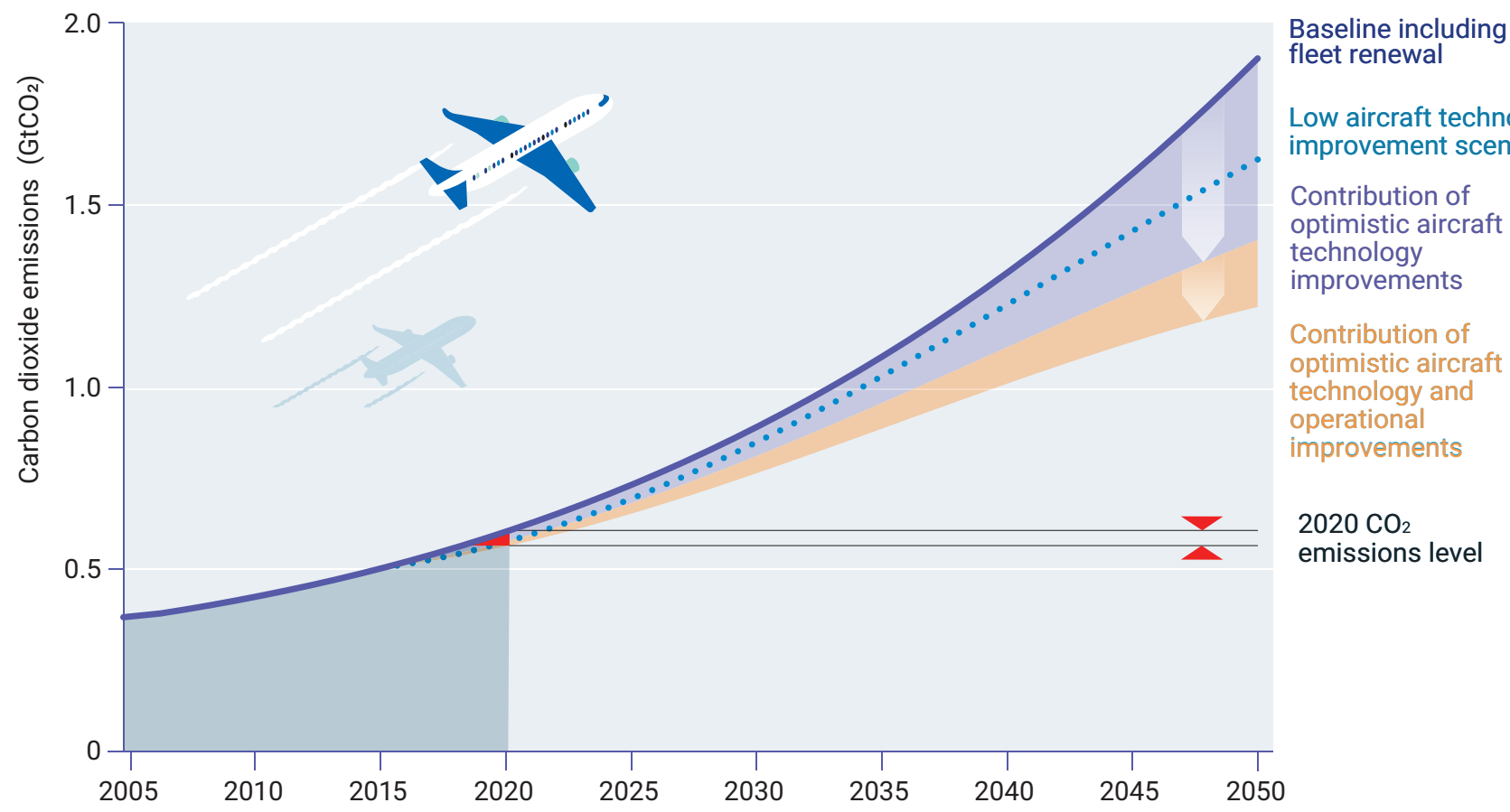

Note: Projections were made prior to the COVID-19 global pandemic.

Source: Fleming and de Lépinay (2019)

Figure 5.2 shows projections of $\mathrm{CO}_{2}$ emissions for international aviation to 2050, and incorporates projected improvements in technology, operations and infrastructure use. These trends assume that growth is unconstrained by airport infrastructure or airspace operational constraints. A wide range of factors, such as fluctuations in fuel prices and global economic conditions, can affect such trends.
The current COVID-19 pandemic has severely affected demand for aviation transport, with 2020 passenger numbers expected to be 55 per cent lower than 2019 levels, and air cargo 12-15 per cent lower (IATA 2020b; IATA 2020c), though it is too early to tell what this will mean in terms of emissions. Current IATA forecasts suggest that short-haul traffic will recover more quickly than long-haul

2 Different data sources and emissions estimation methodologies are used in the literature, which may result in some differences. For example, 'topdown' methodologies are used for IEA data, while Fleming and de Lépinay (2019) use a 'bottom-up' approach for their emissions models. 
traffic. Market analysts suggest that some of the reductions in corporate travel could be permanent, which is supported by the Global Business Travel Association's ongoing polling (Global Business Travel Association [GBTA] 2020). Overall, emissions are likely to increase as traffic recovers, but there is significant uncertainty over the rate of recovery and impact on long-term projections.

\subsubsection{International shipping and aviation emissions and the goals of the Paris Agreement}

Unless States choose to include international shipping and aviation GHG emissions in their initial NDCs, these emissions are not addressed by national policies. The emissions trajectories from the Intergovernmental Panel on Climate Change (IPCC) Special Report on Global Warming of $1.5^{\circ} \mathrm{C}$ (SR1.5) (2018) indicate that global temperature increase can only be limited to no more than $1.5^{\circ} \mathrm{C}$ if $\mathrm{CO}_{2}$ emissions reach net zero by 2050 (interquartile range: 2045-2055), with active permanent removal of $\mathrm{CO}_{2}$ from the atmosphere thereafter. To limit global warming to below $2^{\circ} \mathrm{C}, \mathrm{CO}_{2}$ emissions need to reach net zero by 2070 (66 per cent probability). Based on these pathways, it is clear that international shipping and aviation must be completely decarbonized by around 2050 for $1.5^{\circ} \mathrm{C}$ and by 2070 for $2^{\circ} \mathrm{C}$.

This is illustrated in figure 5.3, which shows combined $\mathrm{CO}_{2}$ emissions from international shipping and aviation as percentages of the available $\mathrm{CO}_{2}$ budget, relative to IPCC illustrative $1.5^{\circ} \mathrm{C}$ scenarios. Without further mitigation action, combined international emissions will consume around 60-220 per cent of the available global $\mathrm{CO}_{2}$ budget by 2050 . This remains the case even when the benefits of technology are included to arrive at the 'low' estimates for fuel usage.

Figure 5.3. Global emissions pathways of $\mathrm{CO}_{2}$ limiting global warming to $1.5^{\circ} \mathrm{C}$ under IPCC illustrative $1.5^{\circ} \mathrm{C}$ scenarios

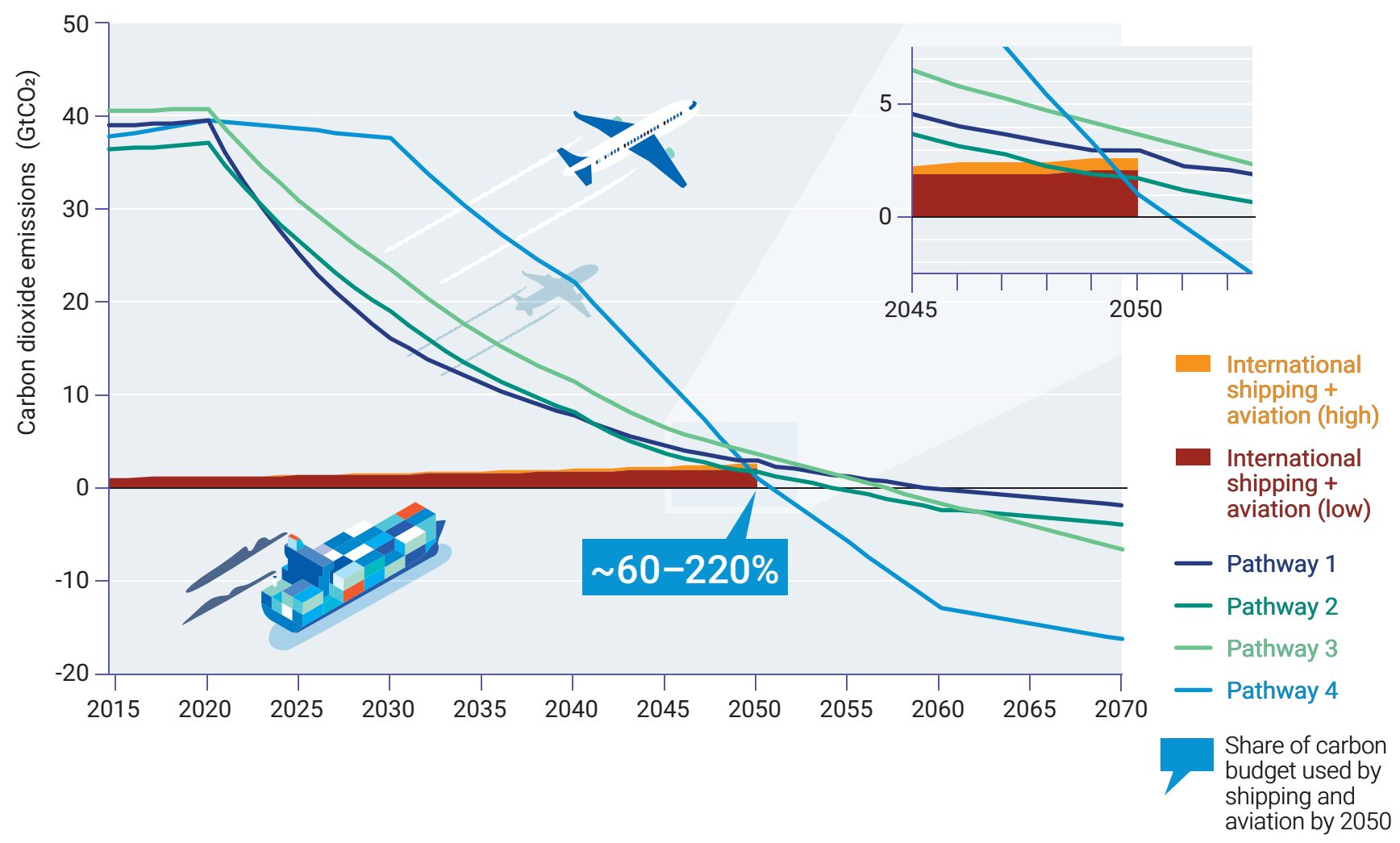

Sources: Pathways redrawn from figure SPM3a, IPCC (2018); international aviation + shipping emissions of $\mathrm{CO}_{2}$ from Fleming and de Lépinay (2019)

\subsection{Mitigation options}

\subsubsection{Shipping}

\section{Improving supply chains and logistics}

There is significant potential to improve efficiencies throughout transport networks, aligning transport demand with size, operations and functionality of ships as well as land-based infrastructure and logistics systems. Improving fleet efficiency can be achieved through increased utilization (for example, reducing ballast leg using larger vessels, assuming the increased capacity is utilized), alternative sea routes that have shorter distances, and reduced speed (DNV GL 2019).

Reducing ships' speed has large emissions reduction potential. The required propulsion power of a ship increases approximately to the third power of its speed. Since 2008, the shipping fleet has reduced its average speed and significantly reduced its emissions, though further reductions are possible (IMO 2020). Reducing the speed of large tankers from 12 knots to 11 knots for example, 
reduced emissions per ton-mile by around 8 per cent. Below 7 knots, the emissions begin to increase again (Lindstad and Eskeland 2015).

\section{Improving ship design and operation}

The newest generation of ships (built after 2015) are typically about 10-15 per cent more efficient than older ships, mainly due to optimized hull design and propeller efficiency and reduced auxiliary loads. This was at least partly driven by regulation on the Energy Efficiency Design Index (EEDI), an IMO efficiency standard that applies to new ships contracted from 2013 (Faber and 't Hoen 2016). Ships built in the next five years may improve by another 15-25 per cent through improved machinery and electricity systems, which could include measures such as hybridization (peak load shaving in conjunction with batteries) and waste heat recovery. Later generations could include a full-scale application of sails and kites, air lubrication and more advanced waste heat recovery, with another 5-10 per cent improvement on average (DNV GL 2017). Operational measures could reduce emissions by a further $5-10$ per cent (DNV GL 2017; IMO 2020).

The total potential of improving the energy efficiency of shipping up to 2050, including logistics and supply chain improvements, speed reduction and ship design and operation, ranges from 35 to 55 per cent compared with 2018 (DNV GL 2019; Balcombe et al. 2020; IMO 2020). Most measures are expected to be cost-efficient with current fuel prices, though wind power, solar panels, air lubrication and waste heat recovery, which require significant investment, need a higher fuel price to be cost-efficient (IMO 2020).

\subsubsection{Aviation}

\section{Technological improvements - engine and airframe}

A recent review (ICAO 2019a) requested by ICAO using independent experts examined the two types of aircraft that burn the overwhelming majority of fuel, the single-aisle (such as the Boeing 737 and Airbus A320) and the twin-aisle (such as the Boeing 777 and 787, and Airbus A330 and A350), and estimated their performance in 10 and 20 years (2027 and 2037). According to the review, radical alteration in aircraft shape is unlikely by 2037, with improvements limited to 'tube and wing' type aircraft. The following targets were deemed challenging but possible by 2037: reductions in fuel burn for single-aisle and twin-aisle aircraft of 21.6 per cent and 21.0 per cent, respectively, which are annual improvements of 1.22 and 1.28 per cent. Prior to the COVID-19 pandemic, in October 2018, IATA forecasted compound annual growth in air travel of 3.5 per cent, which equates to a doubling over 20 years and is considerably greater than the reductions likely to follow from technological improvements.

In the ICAO/CAEP report, independent experts accepted the constraints on design that are currently imposed. In line with current practice, aeroplanes are designed for longer ranges than required, as this gives flexibility in terms of operations and makes resale easier, though at the expense of potential fuel-burn reductions. In a 2010 ICAO review (ICAO 2010), the following additional, but relatively small, savings were identified from changing design constraints:

- reducing the cruise Mach number from $M=0.84$ to 0.78 would give potential savings of around 4 per cent for twin-aisle aircraft

- increasing wingspan for some designs would reduce fuel burn, though this would require wider gates at airports or folding wings (as on the Boeing 777X)

- injecting water into engines to mitigate the hightemperature problems experienced at take-off would improve engine performance during cruise as less turbine cooling air would be required

restricting top-of-climb performance (to make the clime rate smaller) would allow for better optimization of engines.

The independent experts also looked at advanced alternative aircraft types, such as the blended wing body (a design that merges fuselage with a large delta wing), and configurations with wider bodies, smaller wings and engines at the rear of the aeroplane. For the blended wing body, the fuel-burn reduction was 10-12 per cent compared with advanced conventional aircraft. Another alternative design, the Aurora D8, which was studied at the Massachusetts Institute of Technology (MIT) with support from the National Aeronautics and Space Administration (NASA), has wings and a separate fuselage, and offers roughly a 13 per cent improvement. Chen et al. (2019) estimate that blended wing bodies will be 31.5 per cent more efficient in terms of fuel burn than current aircraft. In general, there are likely to be improvements in aircraft airframes and engines in the next 20 or so years, which will improve the burn-fuel metric by around 1.2 per cent per year. However, the crucial conclusion is that the sum of the potential improvements does not come near to matching the projected growth in aviation, let alone to reducing emissions from the current level.

\section{Operational improvements}

In practice, the operation of aircraft is generally less than optimal as they often fly below full capacity and cannot take the best flight route due to diversions and holding patterns. Improved operations could be achieved from, for example, single-engine taxi procedures and ground holds in the terminal area, reduced or de-rated thrust on departure, more direct routing and weather-optimized routing en route, and continuous descent approach (CDA) during arrival. A recent ICAO study calculated that routing inefficiencies currently total 2-6 per cent (Brain and Voorbach 2019). Clearly, the scope for operational improvements to reduce $\mathrm{CO}_{2}$ emissions is limited.

\subsubsection{Alternative fuels}

For both the aviation and shipping sectors, decarbonization cannot occur without a transition away from the fossil fuels 
that they currently burn to alternative fuels. Such fuels could include synthetic hydrocarbon fuels 3 produced from biomass, waste products or $\mathrm{CO}_{2}$ direct air capture (DAC) from the atmosphere (The Royal Society 2019), zero-carbon fuels and energy carriers, such as hydrogen and ammonia (as long as they are produced without generating additional GHG emissions). This section discusses non-fossil alternative fuels for shipping and aviation that have low, zero or negative GHG emissions throughout their life cycle.

\section{Biofuels}

Various biofuels are currently used in shipping and aviation, albeit on a small scale, with estimates suggesting that these will comprise less than 1 per cent of total aviation fuel by 2024 (International Energy Agency [IEA] 2019). While biofuels can have lower life cycle emissions, assessing their merits is complex, as gains towards 'carbon neutrality' depend heavily on their feedstocks and processes, as well as on their direct and indirect emissions, particularly those resulting from land-use change (LUC) from biofuel production. Assuming that biofuel combustion is carbon neutral is therefore a fundamental accounting error that rests on implicit spatiotemporal boundaries and assumptions (Searchinger et al. 2009), as for many biofuels, the energy return on investment is comparatively low or possibly negative (Hall, Lambert and Balogh 2014; Chiriboga et al. 2020). The availability of land and water is also a key and potentially ethical constraint on the availability of biofuel (Nuffield Council on Bioethics 2011).

For shipping, biofuels are currently three to five times as expensive as conventional fuels (CE Delft and Ecorys forthcoming) and are of similar magnitudes for aviation (IEA 2018).

\section{E-fuels from renewable energy}

Other pathways have been discussed for the production of synthetic hydrocarbon fuels, such as power-to-liquid 'electro-fuels' (e-fuels) (Schmidt et al. 2018), or more broadly 'power-to-x pathways' (Kober et al. 2019) (for example, by incinerating municipal waste). The generation of such fuels critically requires the availability of renewable electricity, $\mathrm{CO}_{2}$ and water to synthesize hydrocarbon fuels. To create carbon-neutral fuels, hydrogen needs to be produced via electrolysis powered by renewable energy, while $\mathrm{CO}_{2}$ needs to be taken directly from the atmosphere by DAC and used in Fischer-Tropsch, methanation or methanol synthesis processes. DAC still represents a significant challenge, although some $\mathrm{CO}_{2}$ may be captured from residual emissions, which includes processes such as fermentation and cement manufacturing.

In terms of environmental performance, e-fuels have much smaller land requirements than biofuel and do not depend on arable land (Schmidt et al. 2018), though they do require significant renewable electricity (Fuhrman et al. 2020). Notwithstanding the significant barriers of sufficient available renewable energy and $\mathrm{CO}_{2}$ from $\mathrm{DAC}$, creating synthetic fuel is technologically feasible, though at much greater costs than direct fossil fuel extraction and refining.

In the case of aviation, the use of renewably-generated synthetic fuels (or biofuels) would also benefit the climate through reducing contrail-related warming, due to their absence of soot particles (which are formed from fossil kerosene aromatics and cause the formation of contrails) (Bier et al. 2017; Bier and Burkhardt 2019).

\section{Hydrogen and ammonia}

Hydrogen can be used as a zero-carbon fuel, either in combustion engines or fuels cells. To ensure that hydrogen is carbon neutral, it must be generated from renewable energy sources or reformation of fossil fuels during carbon capture and storage (CCS).

Although liquid hydrogen $\left(\mathrm{LH}_{2}\right)$ has an energy density per unit mass approximately three times greater than aviation kerosene, it has a much lower energy density per unit volume. Thick layers of insulation are also required, which further increases the effective volume. Its use in aviation would therefore require radical aircraft design changes (McKinsey and Company 2020). Similarly, for ships, hydrogen requires about seven times the space of diesel tanks (DNV GL 2019) and would result in a loss of revenue and range. There are also many infrastructural barriers to $\mathrm{LH}_{2}$-powered aircraft or ships, such as generation and distribution, meaning its development is only likely under a larger-scale hydrogenoriented energy economy.

The energy content of hydrogen may be obtained without the problems of cryogenic or high-pressure storage by using a hydrogen-containing compound as a carrier. This is done with hydrocarbons but can also be done with nitrogen to form ammonia. Burning ammonia releases the energy of hydrogen on combustion without producing $\mathrm{CO}_{2}$. Ammonia requires a volume of around 3.5 times the space of traditional fuel tanks (DNV GL 2019). Internal combustion engines can be modified to run on ammonia, though research and development are needed, including on ways to limit emissions of $\mathrm{N}_{2} \mathrm{O}$, a potent $\mathrm{GHG}$ (Valera-Medina et al. 2018)

\section{Full-electric propulsion}

Full-electric propulsion can be carbon neutral if the electricity is generated without emitting $\mathrm{CO}_{2}$ (Epstein and O'Flarity 2019). However, a major barrier in both aviation and shipping is that the energy stored in batteries per unit mass is around $250 \mathrm{~W}$-hr/kg, whereas hydrocarbon fuel has a calorific value of around 12,000 W-hr/kg. In addition, electrical machinery and control units are heavy and large. 
For aircraft, the heaviness of batteries means that batterypropelled aircraft will be limited to shorter ranges. A recent paper by Langford and Hall (2020) states that electric propulsion makes economic sense for ranges between 50 and 200 miles, meaning it will only slightly contribute to reductions in aviation sector emissions. Similarly, batteries can be used as propulsion energy for ships undertaking short voyages, most obviously ferries, but not long voyages unless radical improvements are made.

\section{Implications and key challenges: a focus on price signals and economic incentives}

There are several options that the shipping sector can take to transition away from fossil fuels. Techno-economic analyses from the last two years (Ash and Scarbrough, 2019; Lloyd's Register [LR] and University Maritime Advisory Services [UMAS] 2019; DNV GL 2020; IEA 2020) all indicate that sustainable ammonia is the cheapest decarbonization option for shipping in many scenarios, and would only require a small evolution in current on-board machinery. However, the technology is just in development and full-scale pilots are unlikely for another three years, thus prolonging the period of uncertainty in least-cost fuels.

Non-hydrocarbon fuel options for aviation require radical airframe/engine and infrastructural changes. In contrast, 'drop-in' fuel options, which include alternative hydrocarbon fuels such as biofuels and e-fuels, require little or no changes to aircraft, though they still emit $\mathrm{CO}_{2}$ when combusted in engines. Despite this, drop-in fuels achieve greater climate benefits compared with the life cycle of conventional jet fuel.

The use of alternative low- or zero-carbon fuels will involve massive investment, most of which (90 per cent) will finance the production and distribution infrastructure required, with far less required for on-board engines and fuel storage (Carlo et al. 2020). For operators, this will be reflected in the cost of fuel, which is significant for both shipping and aviation. Future carbon-neutral and zero-carbon fuel prices are estimated to cost in the range of US\$20-100/GJ, which is significantly higher than current aviation fuel costs of around US\$7.5/GJ. IEA estimated that the mean production costs of aviation biofuels in 2018 were approximately two to three times that of fossil jet kerosene (IEA 2018). The major uncertainty lies in the cost and availability of the primary energy sources, such as sustainable biomass and renewable electricity (DNV GL 2020; IMO 2020; LR and UMAS 2020). Shipping fuels traded at around US\$8-9/GJ in summer 2020 (Ship \& Bunker undated), although recent prices have reached over US\$16/GJ.

A shift to fuels that emit low GHG emissions and are renewable provides a very strong economic signal that will further affect the fundamental inputs to fleet growth scenarios. If higher fuel costs translate into airfares, demand will reduce according to price elasticities, assuming all other factors remain equal. Elasticities for passenger air travel vary considerably (Smyth and Pearce 2008) but could average in the order of -1.1 across travel classes
(Becken and Carmignani 2020). In the case of shipping, supply chains that adapt to these new economic conditions may enable fleets using renewable fuels to modify their services and modernize their technologies in such a way that allows GHG targets to be met with minimal impacts on the growth in demand for shipping services (Halim, Smith and Englert 2019).

Ultimately, the price gap between incumbent fossil fuels and post-fossil fuels represents a key challenge that prevents investment both in the sectors and infrastructure on land. Without sufficiently stringent regulation in place to force or enable a business case for zero-carbon fuel use, these investments are unlikely to flow at the required scale until there is either a customer preference or a price premium for zero-carbon shipping services.

\subsection{Pathways to lower emissions}

Section 5.2 shows that projected emissions from shipping and aviation are incompatible with emissions pathways that are consistent with the Paris Agreement temperature goals, given projected increases and the lack of permanent $\mathrm{CO}_{2}$ removals. This means that the decarbonization options presented in section 5.3 need to be implemented despite their high costs. This section discusses the agreed policy goals for both sectors, concludes that they are not sufficient to achieve full decarbonization by 2050 or well before 2070 and discusses how policies could be intensified.

\subsubsection{Current shipping policies}

In 2011, the IMO adopted mandatory technical and operational energy efficiency measures that were expected to significantly reduce the amount of $\mathrm{CO}_{2}$ emissions from international shipping. These mandatory measures (EEDI/ Ship Energy Efficiency Management Plan - SEEMP) entered into force on 1 January 2013. In 2016, additional amendments were adopted to mandate the collection and reporting of ships' fuel oil consumption data. The IMO's Marine Environment Protection Committee (MEPC) adopted the Initial IMO Strategy on reduction of GHG emissions from ships in 2018, which sets out levels of ambition for shipping emissions. These are stated in the strategy as:

phase out GHG emissions from international shipping as soon as possible through strengthened energy efficiency design requirements for ships

improve the carbon intensity $\left(\mathrm{CO}_{2}\right.$ emissions per unit of transport work) of international shipping by at least 40 per cent in 2030 and 70 per cent by 2050, both relative to 2008

set GHG emissions from international shipping on a declining pathway as soon as possible, reducing the total annual GHG emissions of international shipping by at least 50 per cent by 2050 compared with 2008 as a point on a pathway of emissions 
reductions consistent with the Paris Agreement temperature goals.

The IMO is due to agree on a Revised GHG Strategy in 2023, which will be a key opportunity to update the quantitative targets in line with the latest science, and to remove current ambiguities on their alignment to the Paris Agreement temperature goals. Currently, $\mathrm{CO}_{2}$ emissions from domestic shipping are generally not addressed in NDCs.

\section{Role of non-State actors and national strategies}

The system change required for shipping to decarbonize is considerable and demands industry regulation in order to overcome a range of market barriers and failures. The IMO's most common regulatory target is ships and therefore shipowners, though significant evidence shows that there are many additional energy efficiency barriers and failures (Faber et al. 2012; Rehmatulla and Smith 2015).

Private standards and initiatives to reduce GHG emissions from shipping include the following:

Getting to Zero Coalition: a collaboration of approximately 140 corporations focused on achieving the goal of establishing scalable zero-carbon energy solutions for international shipping from 2030 (Global Maritime Forum 2020)

Poseidon Principles: a commitment to transparent annual reporting of portfolio operational carbon intensity relative to an interpretation of the Initial IMO Strategy by financial institutions representing approximately 30 per cent of the capital invested in international shipping (Poseidon Principles undated).

Sea Cargo Charter: a commitment to transparent annual reporting of supply chain operational carbon intensity relative to an interpretation of the Initial IMO Strategy by charterers and cargo owners (Sea Cargo Charter undated).

Altogether, these create a growing set of decarbonizationaligned initiatives that will move capital and purchasing decisions and hold organizations accountable to the Paris Agreement temperature goals. Their connection to the Initial IMO Strategy and Paris Agreement temperature goals indicates that a clarification of the IMO's ambitions within its Revised Strategy could be easily translated into further private sector action.

\subsubsection{Current aviation policies}

ICAO, as a specialized United Nations organization, has the lead role in steering the aviation industry's response to climate change goals. It has developed two global aspirational climate change goals for international aviation, which are to improve fuel efficiency by 2 per cent per year until 2050, and to achieve carbon-neutral growth from 2020 onward. ICAO Member States have identified four main elements in a 'basket of measures' to achieve these goals: aircraft technologies, operational improvements, sustainable alternative fuels and a market-based mechanism. Member States are also exploring the feasibility of a long-term aspirational goal for international aviation (ICAO 2016; ICAO 2019b).

The means of in-sector reductions include aircraft technology improvements through the Aeroplane $\mathrm{CO}_{2}$ Standard (ICAO undated a), along with guidance on operational improvement measures to minimize fuel burn (ICAO undated b) and sustainability criteria for aviation fuels. The Aeroplane $\mathrm{CO}_{2}$ Standard is expected to deliver incremental reductions in line with historic improvements in efficiency. Recent reports suggest that about 1.2-1.4 per cent in fleet efficiency gain is possible per year (ICAO 2019; Fleming and de Lépinay 2019), which falls short of the ICAO target of 2 per cent per year and is significantly less than the projected annual growth in aviation.

The route taken by ICAO to achieve carbon-neutral growth is being predominantly pursued via out-of-sector measures, in particular through the offsetting element of the Carbon Offsetting and Reduction Scheme for International Aviation (CORSIA), which sets a target of not increasing net $\mathrm{CO}_{2}$ emissions from international aviation over average 20192020 levels for the 2021-2035 period (ICAO 2020). ${ }^{4}$ CORSIA will require airlines to purchase eligible units to offset emissions above the baseline. Airlines can reduce their offsetting requirement by claiming emission reductions from CORSIA eligible fuels, thus incentivizing the use of fuels with a lower carbon footprint. It is crucial that the UNFCCC and Member States provide clarity on mechanisms to avoid double counting of units. The nature of offsetting means that there will be no absolute reductions in the aviation sector itself through the use of such credits, and could in fact result in a potential increase in $\mathrm{CO}_{2}$ emissions. Instead, aviation relies on other sectors' avoidance or removal of carbon. By not only continuing to emit but potentially increasing emissions, the net effect will be that no overall reductions can be achieved. This outcome is in stark contrast with the reduction pathway necessary for limiting warming to within $1.5^{\circ} \mathrm{C}$ (Becken and Mackey 2017). Furthermore, the ambiguity of international aviation's $\mathrm{CO}_{2}$ emissions in the Paris Agreement is a constraint to multilateral regulation.

Regardless of concerns around the net benefit of offsetting, Scheelhaase et al. (2018) estimate that CORSIA will result in the offset of only 12 per cent of total international and domestic aviation emissions by $2030 .{ }^{5}$ Currently, offsets

4 This only refers to growth over and above the 2019-2020 levels. Owing to COVID-19 air travel disruptions, the ICAO Council has changed the baseline for the CORSIA pilot period to 2019 levels.

5 CORSIA only addresses international emissions. 
are almost exclusively provided by emissions avoidance. At a hypothetical maximum, if additionality is assumed, only 50 per cent of the emissions will be 'offset' (Becken and Mackey 2017) as the 'baseline' is an intention to emit two units of $\mathrm{CO}_{2}$; if the avoidance is achieved, aviation still emits one unit. However, additionality is controversial as it inherently cannot be proven (Warnecke et al. 2019). More speculatively, it is possible that in the future, offsets particularly sequestration offsets such as afforestation/ reforestation - may become scarce as States use them in their NDC accounting (which also presents a potential double-counting issue).

CORSIA sits alongside several other policies, most notably the European Union Emissions Trading Scheme (EU ETS) that currently includes intra-European flights. How European flights will be treated in terms of compliance with both the EU ETS and CORSIA remains a point of uncertainty (Erling 2018; Scheelhaase et al. 2018; Maertens et al. 2019).

\subsubsection{Intensifying policy measures to achieve decarbonization}

The previous section shows that decarbonization of shipping and aviation in line with the Paris Agreement is very challenging but necessary and feasible. It requires policies that specify energy consumption reduction targets for existing fleets, along with policies that aim to achieve a rapid transition away from fossil fuels to alternative fuels with a lower carbon footprint. Policy instruments related to the introduction of new fuels should incentivize an early adoption phase this decade and take a full life cycle approach to emissions accountancy (DNV GL 2020). Policies should aim to rapidly scale the deployment of new fuels as soon as possible (given the long lifetimes of assets), encourage investment in production processes and ramp up the required generation of renewable electricity.

Suitable regulation to bridge the fuel pricing gap could start at the domestic or regional levels. Satellite observations of shipping activity reveal that an estimated 30 per cent of total shipping emissions fall directly within the responsibility of national governments, which is twice the magnitude previously estimated (UCL 2020). Governments could therefore take action on this policy area as part of their NDCs. Domestic or regional actions towards regulating shipping emissions could also prompt ambitious action at the international level (known as 'autonomous interaction' in international law) and serve as a signal to the industry (Martinez Romera 2016)

Given that supply and demand are interlinked, and because investors need to have confidence that fuels will find a market or that ships or aircraft will be able to purchase the type of fuel they require, it takes time to make a transition. Due to these various lag effects, it is important to start the transition early and gradually, taking into account all United Nations Sustainable Development Goals (SDGs).

\subsection{Conclusions}

1. If left unabated, the international shipping and aviation sectors are projected to emit increasing amounts of $\mathrm{CO}_{2}$ and other $\mathrm{GHG}$ emissions in the coming decades. $\mathrm{BAU}$ scenarios indicate that international emissions from these sectors will consume between 60-220 per cent of allowable $\mathrm{CO}_{2}$ emissions under the IPCC SR1.5 illustrative scenarios by 2050 .

2. Current policy frameworks are insufficient and additional policies are therefore required to bridge the gap between the sectors' current BAU trajectories and GHG pathways consistent with the Paris Agreement temperature goals.

3. Improvements in technology and operations can increase the fuel efficiency of transport if further policies incentivize them. However, due to expected increases in demand (even considering the potential impacts of the current global COVID-19 pandemic), improvements are unlikely to result in decarbonization and absolute reductions of $\mathrm{CO}_{2}$ for either the shipping or aviation sectors.

4. Both sectors will therefore need to combine a maximization of energy efficiency with a rapid transition away from fossil fuel. Fossil fuel substitutes will need to be produced without combustion of fossil fuels, which will require a decarbonization (and rapid scale-up) of new production and supply chains.

5. International aviation currently intends to meet its ICAO goals through heavily relying on carbon offsets, which do not represent absolute reductions, but at best, provide time to transition to low-carbon fuels and introduce energy efficiency improvements. At worst, offsets create a disincentive for investment in in-sector decarbonization and delay the necessary transition. Current carbon offsetting is clearly not a long-term solution and therefore needs to be minimized and eventually phased out. ICAO recognizes this through the CORSIA review scheduled for 2032.

6. For the next few decades it is highly likely that aircraft will be fuelled with hydrocarbons due to their inherent advantages as fuels. Compared with aeroplanes, ships have a less constrained design in terms of volume and mass of fuel, and therefore have greater options, including ammonia.

7. Biofuels can have a lower carbon footprint than fossil hydrocarbon fuels, but this is sensitive to induced LUC emissions, either direct or indirect, which are difficult to quantify. Large-scale production of fossil fuel substitutes will be difficult, expensive and potentially detrimental to the environment. 
8. The hydrogen feedstock used in ammonia and synthetic hydrocarbon fuel will only present net benefits if the production is powered by renewable electricity and if large amounts of $\mathrm{CO}_{2}$ are available without additional combustion of carbon-containing material. The use of synthetic fuels and biofuels in aviation would help reduce warming from contrail cirrus.

9. Although there are large uncertainties surrounding demand and price, the cost of fuel could increase severalfold, regardless of the feedstock and process. Any increases in the cost of fuel will raise the cost of both aviation and shipping. This will likely supress demand, especially for aviation, which may ultimately be the most effective means to manage the sector's emissions.

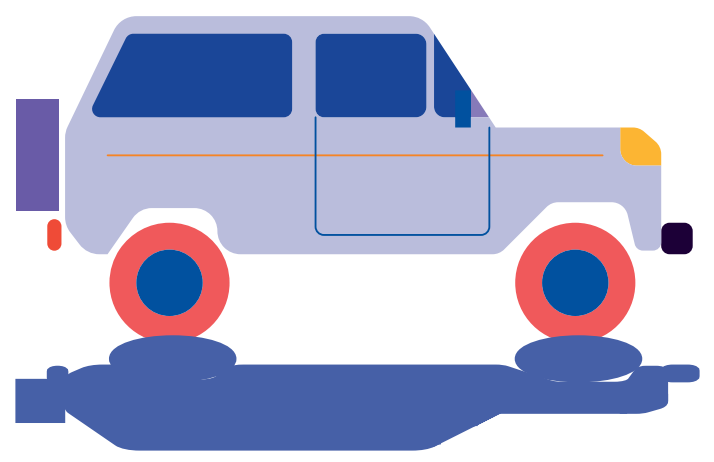

